\title{
Perceived basic needs and resources for the elderly in the peri-urban and rural communities in the Hhohho region in Swaziland
}

\author{
EM Mabuza, DCur \\ Department of Community Health, University of Swaziland.
}

\author{
M Poggenpoel, PhD \\ Professsor, Department of Nursing Science, University of Johannesburg.
}

C Myburgh, DEd

Department of Educational Psychology, University of Johannesburg.

Kev words

Burnout, Home-based caregivers, Stigma, Stress.

\begin{abstract}
Curationis 33 (1): 23-32
The purpose of the study was to explore and describe the basic needs and resources for meeting the needs of the elderly in the peri-urban and rural communities in the Hhohho region in Swaziland. A qualitative, exploratory, descriptive and contextual research design was used. The study population consisted of the male and female elderly aged from 60 years old and above, and key informants (health motivator, community leaders and members from welfare organizations that serve as advocates for the elderly in Swaziland). Purposive sampling was utilized to select participants who met the inclusion criteria. Data were collected using focus groups and individual in-depth face-to-face interviews till data saturation was achieved as evidenced by repeating information. Tesch's method of qualitative data analysis was utilised to identify themes. A total of 30 elderly persons and eight key informants participated in this research. From the study findings the researcher identified the following themes: need for resources because of poverty; need for support because of the burden of caring for others; need for health care because of health challenges; need for company because of loneliness, and need for protection because of abuse of elderly persons. Recommendations were made for community nursing practice, nursing education, nursing research and the Ministry of Health and Social Welfare.
\end{abstract}

\section{Correspondence address}

Prof Marie Poggenpoel,

Department of Nursing Science,

versity of Johannesburg,

Box 524, Auckland Park, 2006

Tel: 0115592860

Fax:011 5592257

E-mail:mariep@uj.ac.za 


\section{Background and rationale}

Old age is defined by Stanhope and Lancaster (2004:546) as people who are 65 years old and above. The term elderly in the context of this study will be used to describe those people who have reached the age of 60 years and above. Kinsella (1997:1) and Charlton (2001:1) reported that the Southern African region had the continent's highest percentage of older inhabitants. In 19976.2 percent of population was estimated to be 60 years of age or older, slightly more than in the Northern African region (Charlton, 2001: 1). In a speech Leete (2002:1) in the Valencia Forum stated that population ageing was occurring at a more rapid rate in developing countries. Swaziland as a developing country is no exception to this pattern of population growth, because according to the report on the Swaziland Population and Housing Census (Ministry of Economic Planning and Development, 2000:8), 4.6 percent of the total population were 60 years old and above. The total population of Swaziland in 1997 was 929718 up from 681059 in 1986 (Ministry of Economic Planning and Development, 2000:8).

The elderly thus constitute a significant and growing population group in African countries and especially in Swaziland. They make up a group whose basic needs are not fully understood, and community nurses have yet to offer the full complement of services which the elderly require and deserve. Population ageing is of considerable concern to public health authorities because ageing is associated with the increased prevalence, incidence, and severity of chronic conditions. In this regard disease prevention and health promotion offer a potentially powerfully response to this developing challenge. The challenge to community nurses is that they must study the needs of this group and respond with appropriate and effective interventions (Spradley, 1990: 597).

In Swaziland, traditionally all the needs of the family members including those of the elderly were taken care of by the extended members of the family. The extended family members had a responsibility of providing food, security, and also cared for the sick and the infirm.
But, with changing times more and more adults in the rural areas have migrated to the urban areas in search of job opportunities and money (Ministry of Health, UNICEF, UNFPA and WHO Final Report, 1995:9).

The traditional image and roles of the elderly are also changing. According to Banga (1994:68), various factors are playing a role in this regard. Education for instance has brought into conflict the traditional roles and authority of the elderly. Many old people have no access to their children and grandchildren to impart their knowledge, experiences and wisdom to the latter. Teachers and other contemporary social leaders are now counsellors from whom the young seek advice. The ideas acquired from schools are often inconsistent with traditional values and customs. Banga (1994:69) also stated at an International Conference on Ageing in Africa, that it was noted that because of the lack of education of elderly people, they lose their powers and find themselves deprived of their contribution in economic and judicial matters and of their role of transmission of knowledge. Banga (1994:70) concluded that "it seems it is more serious in rural areas where older person's authority is now questioned by the younger generation who want to implement the new techniques they have learnt from school and from other contemporary leaders". But, despite the questioning of the older person's authority, they are still expected to care for the very young children of their sons and daughters who may have either left home to seek employment in the cities, or have died as a result of a variety of causes including HIV/AIDS.

\section{Problem statement}

The elderly population is increasing, as indicated by the 1997 Census that 4.6 percent of the population in Swaziland was 60 years old and above. Many of them live in poverty and under very difficult circumstances. There are many ageing people for whose care society has not been able to make provision, and indeed about whose needs society is largely ignorant due to the lack of substantive research information on their needs. Urbanisation and the disintegration of the extended family continue to threaten the security of the elderly. With the social changes that are occurring, a new image of the elderly is also emerging and with it, new dimensions regarding the care and welfare of the elderly are also emerging. These new dimensions regarding their care pose a challenge and burden upon communities in which they live, and also to the community nurses and the Ministry of Health and Social Welfare (2003:42). The elderly continue to experience difficulty in accessing services due to lack of transport and, with the current emphasis of health care programmes being on maternal and child health, there is serious concern that resources are being shifted away from needed geriatric care at a time when growth in the older population is accelerating (Ministry of Health, 1983:8; Ministry of Health and Social Welfare, 2006: 1 \& 13; Mabuza, 2008: 10 \& 11). The research question that arose was: What are the perceptions of the elderly and key informants ( health motivator, community leaders and members of welfare organizations who serve as advocates for the elderly in Swaziland) about the basic needs and the resources for the elderly in the Hhohho region?

\section{Research objective}

The research objective for this study was to explore and describe the perceptions of the elderly and key informants about the basic needs and resources for elderly persons in the periurban and rural communities in the Hhohho region in Swaziland (Mabuza, 2008:12).

\section{Definition of key concepts}

Perception: The term perception refers to the experience of sensing, interpreting, and comprehending the world in which one lives. This makes perception a highly personal and internal act (Kneisl, Wilson \& Trigoboff, 2004:143). In this research perception refers to elderly and key informants perceptions about the basic needs and resources for elderly persons in the peri-urban and rural communities in the Hhohho region in Swaziland.

Basic needs: The elderly, like any age group, have physiological, safety, love and belonging, self-esteem, and selfactualisation needs. Their physical, emotional, and social needs are com- 
plex and interrelated (Spradley 1990, 604-607).

Resources: Resources in the elderly person's environment include any assets or means of facilitation in the the promotion of health (University of Johannesburg, 2010:7).

Elderly person: The elderly person is an individual from sixty years and older (Central Statistics Office, 1997:3).

Community: A community is an identifiable group of persons who share a common interactive pattern and/or geographical location (University of Johannesburg,2010:5). In this research community referred to the elderly living in the peri-urban and rural communities of the Hhohho region in Swaziland.

\section{Research design and method}

The research design and method will be described below.

\section{Research design}

A qualitative, explorative, descriptive and contextual research design was followed in this study (Mabuza, 2008: 26-28). A qualitative design was chosen in order to explore the field. The qualitative research method is largely an investigative process where the researcher makes sense of a social phenomenon by contrasting, comparing, cataloguing and classifying the object of the study (Miles \& Huberman, 1994:104). An exploratory and descriptive design was used, where qualitative research methods were followed to explore and describe the perceptions about the basic needs of the elderly and the resources for meeting these needs (Brink \& Wood 1994:119). The context of the research was the periurban and rural communities in the Hhohho region where the elderly were found. The elderly were from a low socio-economic status with only primary school education. Although these elderly were part of extended families they did not receive any financial or social support from their adult children and other relatives.

\section{Research method}

Sampling, data collection, data analysis, literature control, measures to en- sure trustworthiness, and the ethical principles adhered to in this study are discussed.

\section{Population and Sampling}

The population for this research included elderly and key informants.

Purposive sampling meaning a conscious and intentional selection, was utilised to ensure that the elderly members and key informants who participated in the interviews were the ones who met the sampling criteria (Burns \& Grove, 1993:246; Tesch in Creswell, 1994:148). Criteria for the purposive sampling of the elderly included that they were 60 years and above, lived in the peri-urban and rural communities of the Hhohho region in Swaziland, and that they were from a low socio-economic status. Criteria for the purposive sampling of the key informants included that they were knowledgeable about the needs and resources of the elderly in the peri-urban and rural communities in the Hhohho region of Swaziland (Mbuza, 2008:30).

\section{Sample realization}

Included in the sample were 30 elderly persons, eight males and 22 females, from the ages of 60 years and above, and eight key informants, including the rural health motivator, the key leader in one of the peri-urban communities and also a councillor, social welfare officers, members of the Philani Maswati Charity Organisation and Umftunti Association who act as advocates for the elderly in Swaziland (Mabuza, 2008: 57-59).

\section{Sample size}

Since this research was qualitative in nature, the researcher was committed to obtaining a clear and in-depth understanding of the perceptions about the basic needs and the resources for meeting these needs from the participants' perspectives through data saturation. Hence, the size of the sample was determined by the principle of saturation (Morse, 1994:104; Streubert \& Carpenter, 1999:25). Interviews were conducted till there was a repetition of information regarding the needs and resources of the elderly (Mabuza, 2008: $31)$.

\section{Data collection}

Eight individual in-depth face-to-face interviews were conducted (De Vos, Strydom, Fouche, Poggenpoel \& Schurink, 1998: 126; De Vos, Strydom, Fouche \& Delport, 2002: 297) with the key informants in order to understand their perceptions regarding the basic needs and resources of the elderly in the Hhohho region in Swaziland (Mabuza, 2008: 37-39). The question that was asked of the key informants in Siswati was: "What are your perceptions about the basic needs of the elderly, and the resources for meeting these needs in the peri-urban and rural communities in which elderly live in the Hhohho region?" Three focus group interviews (Krueger, 1994: 75-80) were conducted with the elderly to achieve an in-depth exploration of the phenomenon in question (Service, 1989:4; Mabuza, 2008: 31-37). The same question asked of the key informants was posed to the elderly. All the interviews were audio-taped and transcribed by the researcher (Mabuza, 2008: 39). A pilot study was conducted as a preparatory undertaking for the main research project. One focus group was conducted with the elderly and one indepth interview was conducted with a key informant, as part of the pilot study, to assess if the research question elicited the information on perceptions about basic needs and resources for elderly. These interviews were included in the data analysis of all interviews as the research question did elicit appropriate information for the research. During the process of data collection, the researcher assumed a neutral position (intuition); preconceived ideas were bracketed in an effort to avoid bias in the research (Burns \& Grove, 1993:80). Field notes of the observations in the study were kept by the researcher (Mabuza, 2008: 39).

\section{Data analysis}

All the transcriptions of the interviews and field notes were analysed. Tesch's method of open coding (Creswell 1994:155) was utilised in analysing data in this research. The researcher identified themes and supporting categories pertaining to the perceptions of the basic needs of the elderly and the resources for meeting these needs in the data. Raw data were also sent to an independent coder together with a letter explaining the Tesch's method of data analysis that should be used for the analysis of data After the analysis of 
the data, the researcher and independent coder met for a consensus discussion on the themes and supporting categories (Mabuza, 2008: 39-42). The results were then translated into English.

\section{Literature control}

The results were discussed in the light of relevant literature and similar studies to verify the results, namely, to place them in the context of what is already known (Streubert \& Capenter, 1999: 20; Mabuza, 2008: 42).

\section{Trustworthiness}

The model of Guba and Lincoln (1985: 295-331) for trustworthiness in qualitative research was used. The model of Guba and Lincoln (1985: 295-331) was used because it is comparatively well developed conceptually and has been used by qualitative researchers, particularly nurses and educators, for a number of years (Krefting, 1991:215). Within this study (Mabuza, 2008: 4655 ) the following four criteria to ensure trustworthiness of this research are truth-value, applicability, consistency and neutrality. Applying strategies of credibility ensured truth-value. The researcher spend several years working with elderly in the Hhohho region. She kept a reflexive journal when she interviewed the participants; used different methods of data collection (focusgroup interviews, in-depth individual interviews, observation and field notes); used more than one data source (elderly and key informants); had peer reviews from supervisors; checked the themes and categories with the participants, and focused on the perceptions of the basic needs and resources for elderly. Applying strategies of transferability ensured applicability. The researcher provideda clear description of the demographics of the participants, and gave a dense description of the results with supporting direct quotations of the participants. Similarly applying strategies of dependability ensured consistency. A dense description was given of the research methodology used in this study. Neutrality was ensured by confirmability. A chain of evidence of the whole research process was provided (Lincoln \& Guba 1985:290).

\section{Ethical principles}

Ethical principles were applied accord- ing to the guidelines of the Democratic Nursing Organization for South Africa (1998:3-6). The principles of ethical research that were adhered to in order to ensure the quality of research included confidentiality and anonymity, privacy, consent, beneficence, and feedback (Mabuza, 2008: 43-45). These ethical principles were applied in the following manner. During the whole research process the participants were not identified. They were interviewed in venues of their own choice where they felt comfortable. All participants gave written consent after the research was explained to them. The participants could withdraw at any time without penalty. The participants benefited through this research because they were enabled to express their perceptions on the needs and resources for the elderly in periurban and rural communities. The Department of Health officials have taken cognizance of the results of this research and have made policy changes to ensure that the needs of the elderly are catered for. All the participants received feedback on the research results.

\section{Research findings}

Five themes were identified during data analysis in which Tesch's descriptive method of analysis (Creswell, 1994: 155) was utilised. The themes are: need for resources because of poverty; need for support because of the burden of caring for grandchildren and others; need for health care because of health challenges; need for company because of loneliness; and need for protection because of abuse.

\section{Discussion of findings}

\section{Theme 1: Need for resources because of poverty}

The study highlighted the needs of the elderly and a lack of resources including food security, housing, clothing, water supply and basic sanitation, electricity supply and financial resources (Mabuza, 2008: 59-79).

All the participants reported that: "Kudla akweneli. Sitfola sinkhwa kanye ngeliviki ngabo Lwesibili eSalvation Army. Letinnye tinhlobo tekudla letenta emaseko lamatsatfu asititfoli". (Food is not enough. They only get bread once a week on Tuesdays only at the Salvation Army Centre. They do not get food that contains the three food groups).

Masango (2005:11) reported that: " $A$ poor 70-year-old man of Macambeni in Piggs Peak lives with his nine year old granddaughter. The ageing man was left to look after his daughter after the demise of his wife and son. He and his granddanghter had been scavenging for food from bins and take away outlets in Piggs Peak".

One of the key informants from the individual interviews stressed that:

"There is need for clothing for the elderly, because nowadays you only have to wear your clothes two or three times and they need to be washed. You need soap to wash these clothes. Then this question is answered by the financial capacity or economic status of this person".

The same key informant further stated that the elderly found themselves having to distribute the little money they had to all the basic nceds that arose each day: "Hence, there was dire need to get a sizeable income so as to be able to purchase the necessary clothing, especially winter clothing".

When asked to explain what he meant by being poor, he said: "Ngisho kokwembatsa. Ngite timphahla tekuvunula tekumbatsa phela". (He does not have Swazi attire to put around his waistline.)

One of the key informants said: "The elderly people have to provide food and clothing and even if school fees are free they have to pay levies and buy uniforms".

When discussing the problem of poor housing, the participants in the focus groups reported that: "Silala ngaphandle". (They are sleeping outside.)

One of the key informants also confirmed that: Destitute elderly slept outside in a shack made of sacks".

The structures were falling apart; they were in a dilapidated state; others did not have houses of their own. One of the elderly said: "E... ngite 
indvodzana lengagakhela indlu yokulala". (She has no son who can build her a house).

The focus group participants in the peri-urban communities unanimously reported that: "Letindlu lesihlala kuto tivadzilika". (The houses they are living in are in a terrible state some of the participants complain that the rooms they are allocated to are collapsing).

A key informant said: "Tidzingo tabogogo basically badzinga emakhaya ekuhlala. Some of them lapha bahlala khona are shambles kute lobanakekelako". (They do not have decent clothing due to poverty. The Roman Catholic Mission provides them with blankets only).

Kaseke (1998:3) is of the opinion that it is not surprising that poverty has become a serious problem in Swaziland. Many people did not benefit from the economic growth achieved in the 1970's and 80 's. In addition the problem was also exacerbated by the lack of a comprehensive social security system in Swaziland (Magagula, 2004: 7). Seventy percent of Swaziland's population live in poverty, and a quarter rely on food aid for survival, of which the elderly are also part. High unemployment in the formal economy and the social impact of HIV/AIDS have pushed 69 nine percent of the population into poverty (Ngidi, 2004: 3).

\section{Theme 2: Need for support because of the burden of caring for grandchildren and others}

The burden of caring for grandchildren who were orphans due to HIV/AIDS related illnesses and others; chronic illnesses were also reported.

"Labanimngi betfu asinakwa bantfwana betfu. Solo sibhekeke kokutsi sinakekele tihlobo kakhulu batukulu betfu". (Most of them are neglected by their own children, but they are still expected to take care of other relatives, especially children and grand children).

Most participants in focus group interviews, especially the peri-urban elderly, reported the problem of normal services provision when they said: "Site emanti lamaning lahlobile. Kubita kutsi siye emfuleni lose dvute siyowasha loko lokungcolile. Site gesi nemithoyi lebesinayo seyidzlikile". (They have no water supply and therefore have to fetch water from the nearby streams and rivers for cooking and laundry. They also do not have electricity supply. The toilets that they have were destroyed).

Noumbissi (2004:1) reported that more than $40 \%$ of the elderly population resided in the poorest environments, while about $30 \%$ of adults were in the same situation. Noumbissi (2004: 1) indicated: "About $10 \%$ of the elderly population continue to work in their very old age. Those living in the poorest conditions do not have access to electricity, clean water, garbage disposal and flush toilets. Using water from rivers for drinking and animal dung for cooking man' seriously affect the health and wellbeing of the population especially the elderly who by virtue of age have developed some disabilities and/or degenerative diseases".

The elderly shoulder many caring responsibilities, yet there are very little support given to them; they are caring for their disabled children. Most of them receive help, if any, from outside the family circles and neighbours; as elderly women they have more caring responsibilities for their children and grandchildren; they care for the sick at home who have HIV/AIDS and other related illnesses, which pose a great deal of psychological and emotional strain on them, hence, they are depressed.

Nhongo (2002:1-2) noted that older people were shouldering immense responsibility in the face of food shortages and they faced a multiplicity of problems. It was not uncommon to find older people looking after up to seventeen children. The elderly had to start afresh as breadwinners to look after those children

One of the elderly from the rural communities said: "Sinemifwalo leminyenti yokunakekela labagulako kantsi tsine kute losinakako ngokuselekelela; sinakekela nebantfwana babo labachwalile; labanigi betfu batfola lusito lolungengakanani kubomakhelwane nakulabanye bantfu nje labangesito tihloba labasihawukelako; njengabo gogo futsi sibesifazane, sinemtfwalo lomkhulu wokunakekela laba lagulako lababantfwana betfu nebatukulu; sinakekela labagulela emakhaya labanelgciv'ane le AIDS naletinve tifo letivela ngoba umuntfu asaneli gciwane Loku kusibangela kuhlukumeteka etingcondvweni". (They experience many caring responsibilities, yet there is very little support given to them; they are caring for their disabled children. Most of them receive help, if any, from outside the family circles and neighbours; as elderly women they have more caring responsibilities for their children and grandchildren; they care for the sick at home who have HIV/AIDS and other related illnesses which pose a lot of psychological and emotional strain on them)

Another elderly participant from the peri-urban focus group interviews stresses that the elderly get no assistance when they are bereaved, so much so, that: "Ingatsti umuntfu angaze atibulale". (One feels like committing suicide).

\section{Theme 3: Need for health care because of challenges}

The participants described different challenges in their pursuit of health care including unkind treatment by health staff, lack of resources and a lack of understanding of the needs of the elderly.

They all describe ill-treatment by the hospital staff when the elderly are admitted to hospital.

A key informant said that one of the problems the elderly faced was:

"Poor access to medical and other health care facilities since there is no provision for specialized care designed for the elderly coupled with the negative attitudes of the health workers particularly nurses who can not even offer spiritual care and lack of transport amenities due to unfriendly public bus conductors are an issue".

The elderly participants reported that: "Abasinaki; abasamkeli ngendlela lefanele; sivakubhadalela lokwelashwa; bonesi abasphi kudla noma sow'u dzinga kufuntw'a; sebate nomusa. Abasibhandishi ngesineke; abasiyisi nasemthoyi nalapho 
kugezelwa khona; kute nanemitsi etibhedlela takahulumende". (Services are unfriendly; there is poor reception at clinics; we are made to pay for the treatment; nurses do not feed us and they are no longer friendly. They do not do wound dressings gentle; they do not take us to the bathroom; there is no medication in the government hospitals. They express a lot of unhappiness when they have to go to the government health facilities).

The same negative attitudes from health care workers towards the elderly have been reported in Great Britain (Laurent, 1993: 20). The elderly were regarded as stupid, decrepit, feeble, or unusually eccentric, wise or sweet natured, and in any event to be patronised. These attitudes pervaded the health services and meant that services were based on deep-seated stereotypes of what old people were like, rather than what they needed. The negative attitude towards the elderly in an article by Pick'n Pay (2003: 2) pointed out that in an increasing youthorientated society, older persons were often made to feel worthless, disrespected and redundant in any sense of the word.

One of the key informants said: "Kute i-organizational structure ngekwekutsi nangabe umuntfu lomdzala angaya kuphi esibhedlela noma unayo noma ute imali kute nje because labanye bakhona bahamba kalukhuni ngalo kwekutsi labanye sebachwalile nemadvolo akasavumi ukhanzda kutsi seba stark lemakhaya kute lolobanakekelako kahle". Kute losinakekelako mayelana nekusimikisa ema-clinic ngani ngoba nebantfwabetfu bayasibukelela kantsi site nalemali yokubhadala esibhedlela". (There is no organisational structure to look at the elderly persons' medical needs and there is no difference between those in the rural and in peri-urban communities in this regard. They also face transport problems).

One of elderly participants in the focus group interviews in the rural setting complains that no one is willing to take them to the clinics, and they do not have money to pay the hospital or health centre as they are neglected by their own children.
The issue of neglect was also discussed by one of the key informants when she explained: "Labanye basenabo bantfwana kodvwa sebafana nekutsi sebafa ngoba abatihluphi ngekunakekela batali babo. Inkinga kutsi ababasiti ngalutfo batali babo kantsi umtali wa spender yonkhe imadlana labekadze anayo amfundzisa khona phela naye atomsita nase aphelelwe ngemandla" (Much as it is true that some of the elderly people have lost their children others still have children. The problem is they do not provide for their parents, yet the parents had spent the little resources giving them education with the hope that they will return the same kindness in the future)

One of the key informants expressed concern: "Sisahamba singuPhilani MaSwati silitfolile litfuba lokubuketa letindzawo both emakhaya nakhona lapha emadolbheni sibuka yona inhlala kahle yebantfu labadzala. Sibonileke lapho kutsi baphatsekile bagula kakhulu. Kubanetıfo nje tekutsi umuntfu sowukhulile. Bakhala nje ngemadvolo; bakhala ngaboshukela bayabahlupha kakhulu; bo $B P$ nalokunye kephabayephuta kuya esibhedlela. Tizatfu tiningi kungaba kutsi kute imali nekutsi bangaphatseki kahle nasebefikile emtfolamphilo bese loko kubenta banconote kufela emakhaya". (When they go to the communities, rural and peri-urban, as members of the Philani MaSwati Charity Organization, the elderly that they meet complains of diabetes, arthritis and hypertension but delay in seeking treatment.

Reasons for the delay can vary from lack of financial resources to inaccessibility of health facilities in terms of the negative attitudes of health workers hence; they prefer to die at home.) "kunokutsi siphatseke kabi singamane sifele emakhaya". (Rather than be humiliated, they would rather die at home).

They unanimously reported that: "Lusito lwetemphilo silutfola e Salvation Army Clinic nase Loma kuphela". (The only available assistance they receive at least once a week is from the Salvation Army Centre and the Roman Catholic Church based in Mbabane.)

\section{Theme 4: Need for company because of loneliness}

Emotionally, a considerable number of participants in the focus group interviews expressed a sense of despondency.

They indicated that: "Sesiphila ngekutsi siye emasontfweni ngoba sengilapho sitidvudvuta khona". (Nothing bring them happiness and they only rekindle their hope by going to church. Church is a place where elderly get spiritual comfort for everyday problems).

Leete (2004:5) stated that recent investigation showed that an increasing number of old people wished to die at home. Most elderly persons in the focus group interviews confirmed this as one of the key informants said: "If nobody pays attention to them, by just conducting a church service with them they end up getting hurt as she or he lacks strength to even afford to go to the nearest church centre".

This finding is in line with the responses of nurse participants in the research on the spiritual needs of older people (Narayanasamy, Clisset, Perumal, Annasamy \& Edge, 2004:13) who have concluded the need for comfort and reassurance was significant.

In all the focus group interviews participants reported: "Labanye betfu bate bantfuana; bate emadvozda afa; bantfwabetfu babatsetse bantfwana babo kitsi bahamba nabo; bantfuana betfu bemantfombatana bahamba bayokwendza; bashiywa ngemadvodza nebafati babo bemuka; liningi letfu sesite batali; labanye betfu asizange sendze; nokutsike kute idzawo yokuchitsa situnge". (Some of them are childless; being widowed; the children have been taken away from them by their parents; husbands died; jilted by their spouses; their children married and left; most of them have no parents; a few of them never married and there are no recreational facilities for the elderly).

Participants reported that they were living alone because of the death of their spouses or neglect by their own family members. They were left alone to care for the grandchildren because their 
parents had died. The burden of burying their children was highlighted in almost all the responses. Also highlighted by the study was the indication of the need for company, element of abuse and neglect by relatives including their own children needing social support.

\section{Theme 5: Need for protection because of abuse}

The concern on abuse was emphasised by one of the key informants, when he mentioned that the grandmothers were raped, sometimes by their grandchildren and beaten using all sorts of weapons.

One elderly woman in a focus group cried and said: "..h ...mm we are abused. But I am not able to explain because of the presence of these men in this group".

This was supported by several reports in the local newspapers as described below. As confirmation that the element of abuse was prevalent, the local newspapers also cited some incidences of abuse in different communities of Swaziland. For instance, Makhubu (2005:9) reported in the local newspaper that an elderly widow, of 60 , from Elangeni, was indecently assaulted by her 23-year old neighbour who fondled her private parts and tried to rape her while she was sleeping in her house. Makhanya (2005:5) reported that an elderly widow of the Engculwini area stared death in the face on Monday when she was almost stabbed by her enraged son. Dlamini (2005:1) reported in the local newspaper that a 75 -year old bedridden grandmother deteriorated because she was haunted by the criminal act of her granddaughter who had abducted an 18 months old child at Nkoyoyo, Mbabane. She lamented by exclaiming: "Please don't kill me".

\section{Limitations}

The focus of the study was on the perception of needs and resources of the elderly in peri-urban and rural communities in the Hhohho region. This research was contextual in nature and can not be generalized to all the elderly in Swaziland. It would be helpful to also try to get a description of how the elderly in other regions in Swaziland would perceive their needs and resources.

\section{Recommendations}

Recommendations were made in reference to community nursing practice, nursing education, nursing research and the Ministry of Health and Social Welfare discussed below:

\section{Community Nursing Practice}

The community nursing fraternity should develop a long-term, multifaceted approach towards improving the health and quality of life of the neglected group of elderly people. Respect and cultural values should be included in the general school curriculum. The aim should be to develop geriatric services (Lipschitz, 2004:608). To address the concern of the spirituality of the elderly could be to engage the services of a chaplain, spiritual counsellor or some other person specialising in the spiritual care of the ill and the dying (McSherry \& Ross, 2002:483). To prevent abuse, community nurses should work with agencies and organisations such as the Swaziland Action Group Against Abuse (2004-2005:7) that recognizes the importance of gender and power relations and seeks to influence those who make decisions at policy-making and political levels. More information is needed on the causes and consequences of elder abuse, drawing data provided by elderly people themselves (Swaziland Action Group Against Abuse, 2004-2005:7). Optimisation of contacts with friends and relatives should be stressed so as to avoid loneliness and depression. The importance of measures to enable the elderly to continue to attend the church of their choice where they are likely to meet old friends and possibly make new ones is also stressed (Gillespie, 1994:6). If the family refuses placement somewhere else of elderly vulnerable to abuse, legal alternatives for the protection of this elderly should be considered when such negotiations fail (Griffith, 2004: 324-345). There should be provision of health education and case management services to help those elderly persons remain in their homes and empower them to assume an active role in promoting their own health (Wiek, 2000:1)

\section{Nursing education}

The issue of professional education for the care of older people is emphasised in Joy, Carter and Smith (2000:1043) when they state that it is important to include gerontology within pre-registration, higher education diploma and post- registration courses. Nurse practitioners in adult health and gerontology must expand their repertoire of health promotion and health maintenance strategies to meet the needs of this special population (Swenson, 1992). Modules that focus on ageing well including health promotion, disease prevention, maintaining cognitive functioning, social support, and active involvement with life are recommended because they encourage strategies to maximize the potential of ageing well (Hall-Long, Plowfield \& Hayes, 2004:535).

\section{Nursing research}

Research into the relationship between social activity and life satisfaction amongst the rapidly growing population of the elderly is recommended (Gillespie, 1994:6). Community nurses must take the lead in incorporating the findings of research about health promotion into clinical practice and protocols and into the community partnerships and programmes so as to benefit efforts for meeting the basic needs of the elderly (Pender, 2003: 4). A collaborative project of research in spiritual and spiritual care in nursing from a Christian World View is crucial to provide nurses with evidence-based knowledge to guide their giving of spiritual care, an essential aspect of wholistic health care (Van Dover, 2002:2). Twigg (2004:1) suggested that outreach workers can be trained to identify depression among communitybased elders and that interventions can be successful in ameliorating the concerns expressed by depressed, isolated elderly persons.

Ministry of Health and Social Welfare Medical care expenses should be obtained from family resources, because medical care, as a non-discretionary expense, is a sort of necessity. Policy, research and programme initiatives are needed to communities affected by the HIV/AIDS pandemic to identify and address the health needs of the caregivers (Ministry of Health and Social Welfare, 2003:7). Government should provide food, clothing and shelter as basic necessities to the elderly. The state must by legislation and other measures, within its available re- 
sources, ensure the progressive realisation of the right to sufficient food for the elderly (Kingdom of Swaziland, 1998:20). Providers of palliative care are needed, and that different diseases require diverse parameters for the planning of rational palliative care treatment and team organisation. In addition of to the legislative incorporation of the palliative care a long-term strategy at the national and local level is needed, with defined palliative care services and providers (Stambuk, 2004: 2). Health and medical services should be free of charge and nurses should be gentle and friendly to the elderly. Doctors must not only treat the elderly but must make the access to medical treatment as easy as possible (Bloom, 2005:12). A new age care training programme should be developed. The training programme's objectives, well worth noting should be to develop the special skills as essential to age care (Bulletin on Ageing, 2000:3). Government needs to develop comprehensive strategies to stop abuse, including a supportive legal framework, and there needs to be public education and training for public sector staff to equip them to detect and act on abuse (Russell \& Basser, 1998:105). Social welfare officers should recommend transportation-friendly communities and an adequate infrastructure to enhance mobility. They should create opportunities to promote healthy ageing since they often serve as members of the multidisciplinary teams (Marshall \& Altpeter, 2005:141142).

\section{Conclusion}

The research objective of this study was to explore and describe the basic needs for the elderly and resources to meet these needs in the peri-urban and rural communities in the Hhohho region in Swaziland. Qualitative in-depth interviews were conducted with elderly participants and key informants. Rich data were obtained from these interviews. It was clear from the results that the elderly in Swaziland are a neglected population. The elderly and key informants expressed concerns about poverty, lack of access to health services, the burden of caring for others, loneliness and abuse.

\section{References}

BANGA, E H 1994: Social Changes in the Emerging Images of the Aged in Ghana: Social, Health and Nursing Implications in Nursing Education in Ghana for the $21^{\text {st }}$ Century. Accra: Woeli Publishing Services.

BLOOM, G 2005: Health and Social Protection: Meeting the Needs of the Very Poor. Health Policy 57(3): 205-224

BRINK, PJ \& WOOD, MJ 1994: Basic Steps in Planning Nursing Research. Boston: Jones \& Bartlet.

BULLETIN ON AGEING, 2000: The loneliness of the Elderly Persons. United Nations Economic Commission for Europe, Institute for Older Persons and Social Services, Ministry of Labour and Social Affairs Spain; United $\mathrm{Na}$ tions Population Fund.

BURNS, N \& GROVE, S K 1993: The Practice of Nursing Research. Philadelphia: Saunders

\section{CENTRAL STATISTICS OFFICE} 2001: Report on the Swaziland Population and Housing Census Vol 4 Analytic Report. Mbabane, Swaziland: Central Statistics.

CHARLTON, KE 2000: Qualitative Indications from a Food Expenditure Survey can be Used to Target the Food Insecure in South Africa, Journal of Nutrition 132(11): 3235-3242.

CHARLTON, KE \& ROSE, D 2000: Nutrition Among Older Adults in Africa: The Situation in the Beginning of the Millenium. Journal of Nutrition 13 (1): 1 .

CHARLTON, KE 2001: Nutrition, Health and Old Age - The Case of South Africa Urban Elderly. Journal of Nutrition 13(1): 1.

CRESWELL, JW 1994: Research Design Quantitative and Qualitative Approaches. California: Sage Publications.

DE VOS, AS; STRYDOM, H; FOUCHE, CB; POGGENPOEL, M \& SC; HURINK, EW 1998: Research at Grass Roots. A Primer for the Caring Professions. Pretoria: JL Van Schaik.

DE VOS, AS; STRYDOM, H; FOUCHE, CB \& DELPORT, CSL
2002: Research at Grass Roots. A Primer for the Caring Professions. Pretoria: JL Van Schaik.

DEMOCRATIC NURSINGORGANISATION OF SOUTHAFRICA, 1998:

Position Paper, Ethical Standards for Nurse Researcher. Pretoria: DENOSA.

DLAMINI, N 2005: Bedridden grandmother deteriorate because haunted by criminal act of granddaughter. The Times of Swaziland: 1, 29 November.

GILLESPIE, CWI 1994: Life Satisfaction and Activity in the Elderly. Cape Town, University of Cape Town: Department of Psychology.

GRIFFITH, R 2004: Protecting vulnerable adults from abuse: A case study in the British Journal of Community Nursing; vol.9 (8), 342-345; 2004 in CANE annotated bibliography National Centre on Elderly Abuse (NCEA).

GUBA, E \& LINCOLN, Y 1985: Naturalistic Enquiry. Beverly Hills, California: Sage.

HALL-LONG, BL; PLOWFIELD, L\& HAYES, E 2004: Episodic health Promotion: A Guide to Educating and Interviewing. The Gerontologist. Washington: 44 (4): 535

JOY,JP; CARTER, DE \& SMITH, LN 2000: The evolving educational needs of nurses caring for the older adult: a literature review. Journal of Advanced Nursing 200031 (5), $1039-1045$

KASEKE, E 1998: A Situational Analysis of Social Welfare Services in Swaziland. Mbabane: Webster Print.

KINGDOM OF SWAZILAND, 1998: (Draft A). 2022 National Development Strategy for Swaziland. Mbabane: Webster Print.

KINSELLA, K 1997: Ageing Trends: South Africa. U.S. Department of Commerce Economics and Statistics Administration: BUREAU OF THE CENSUS.

KNEISL, CR; WILSON, HS \& TRIGOBOFF, E 2004: Contemporary Psychiatric-Mental Health Nursing. New Jersey: Pearson Education.

KREFTING, L 1991: Rigor in Qualita- 
tive Research: The Assessment of Trustworthiness, The American Journal of Occupational Therapy, 45(3): 214222.

KREUGER, RA 1994: Focus Groups: A Practical Guide for Applied Research. Thousand Oaks: Sage.

LAURENT, C 1993: Time to Listen. Nursing Times 86(8): 20.

LEETE, R 2002: Poverty Issues in Old Age: Operational Challenges in the Valencia Forum. UNFPA (United Nations Population Fund).

LIPSCHITZ S 2004: The Silver Surfers. Keeping the Elderlv Healthy. 22 (11): 606-608.

MABUZA, EM 2008: A Strategy for Facilitating the Mobilisation of Resources to Meet the Basic Needs of the Elderly in the Hhohho Region in Swaziland. Auckland Park: University of Johannesburg. (Thesis- DCur.)

MAGAGULA, M 2004: Lack of comprehensive security system for rural elderly. The Times of Swaziland: 1, 31 October.

MAKHANYA, K 2005: Elderly widow in Engulweni stared death in the face. The Times of Swaziland: 5,3 February.

MAKHUBU, B 2005: Elderly widow indecently assaulted by neighbour. The Times of Swaziland: 8,4 January.

MARSHALL, VW \& ALTPETER, M 2005: Cultivating Social Work Leadership in Health Promotion and Ageing: Strategies for Active Aging Interventions. Health and Social Work. 30(2): 135-145.

MASANGO, GS 2004: Poor 70 year old man of Macambeni in Piggspeak lives with his nine year old daughter. The Times of Swaziland: 12, 7 September.

MCSHERRY, W \& ROSS, R 2002: Dilemmas of Spiritual Assessment: Considerations for Nursing Practice. Journal of Advanced Nursing. 38(5): 479-488.

MILES, M \& HUBERMAN, M 1984: Qualitative Data Analysis: A
Sourcebook of New Methods. California: Sage.

MINISTRY OF ECONOMIC PLANNING AND DEVELOPMENT, 2000:

Swaziland National Population Policy Framework. Mbabane: Swaziland Government.

MINISTRY OF HEALTH 1983: National Health Policy. Mbabane: Webster Print.

MINISTRY OF HEALTH AND SOCIAL WELFARE 2003: The Health Sector Response to HIV/AIDS PLAN in Swaziland 2003-2005. Mbabane: Webster Print.

MINISTRY OF HEALTH AND SOCIAL WELFARE 2006: National Health and Social Welfare Policy. Mbabane: Webster Print.

MORSE, J M 1994: Qualitative Health Research. Newbury Park: Sage.

MINISTRY OF HEALTH, UNICEF, UNFPA, \& WHO FINAL REPORT 1995: Traditional Birth Attendants Survey, Swaziland. Mbabane: Webster Print.

NARAYANASAMY, A CLISSET, P PARUMAL, SANNASAMY \& EDGE R 2004: Responses to the Spiritual Needs of Older People. Journal of Advanced Nursing. 48(1) 6-16.

NGIDI, P 2004: High unemployment pushed 69 percent of population into poverty. The Times of Swaziland: 1,19 October.

NHONGO, P 2002: In Relief Web: IRIN Retrieved on 01/06/05 from, http:// www.itds/?id=nairobi-case-studv (United Nations.) Accessed I June 2005).

PICK'N PAY 2003: Talk About: The Elderly: Accent on the Youth. http:// www.pick'npav.co.za/pnp/view/pnp/ en/page9689. Accessed 1 February $\underline{2005}$

NOUMBISSI, A 2004: Poverty among the elderly in South Africa. Eldis. The gateway to development information. http://www.eldis.org/ static/DOC17357.htm. Accessed 1 June
2005.

PENDER, J N 2003: Most Frequently Asked Questions about the Health Promotion Model and my professional work and career. Page last modified: Tuesday, 17-May-2005 14:12:45 EDT University of Michigan School of Nursing.

RUSSELL, C \& BASSER, M 1998: Older People's Lives in the Inner City: Hazardous or Rewarding? Australian and New Zealand Journal of Public Health 22(1) 98-107.

SERVICE, R 1989: Conducting Focus Group Research. The Journal of College Admissions. 1989 4-7.

SPRADLEY, BW 1990: Community Health Nursing Concepts and Practice, Illinois, London: Scott, Foreman \& Co.

STAMBUK, A 2004: Palliative Care for the elderly, An Analysis of Needs and Resources in Croatia Part 1: Draft Research Paper. International Policy Fellow, Public Health Society Institute / Center for Policy Studies.

STANHOPE, M \& LANCASTER, J 2004: Community and Public Health Nursing. St. Louis, USA: Mosby.

STREUBERT, HJ \& CARPENTER, D $R$ 1999: Qualitative Research in Nursing: Advancing the Humanistic Imperative. Philadelphia: Lippincott.

SWAZILAND ACTION GROUP AGAINST ABUSE (SWAGAA), 20042005: Annual Report. Manzini: Jubilee Printing \& Publishing.

SWAZILAND NATIONALSTATISTICS 1997: Census. Mbabane: Webster Print.

SWENSON, MM 1992: Primary Health Care of Elderly Women. Journal of American Academic Nurse Practice. 4 (4): 143-147.

TWIGG, P (2004): Mental Health, Substance Abuse and Elder Abuse: Detecting Depression and Promoting Mental Health Among Isolated Elderly. The Gerontologist. 44(1):1-4.

VAN DOVER, L 2002: Research in Spirituality and Spiritual Care in Nursing 
from a Christian Worldview (an NCF Collaborative Project) USA Intervarsity Christian Fellowship. http:// www.intervarsitv.org/ncf/facgrad/ scr.html. Accessed 25 Mav 2004.

WIEK, KL 2000: Health Promotion for Inner-City Minority Elders. Journal of Community Health Nursing. 2000, 17 (3), 131-139. 